of the DNA. This may be the case for the yeast $H I S 3$ (ref. 14) and GALI (ref. $15)$ gene enhancers. The second point is that in some cases bending DNA into a loop may be energetically unfeasible without the intrinsic bending provided by supercoiled DNA. One such example is the arabinose system, which can loop in vitro only when the DNA is supercoiled ${ }^{3}$.
Not only does supercoiling help bring distant points together, but it can also assist formation of complex wrapped structures, such as occurs for the integration complex of the int, xis and IHF proteins of phage $\lambda$ (ref. 16).

Robert Schleif is in the Biochemistry Department, Brandeis University, Waltham, Massachusetts 02254, USA.

\title{
Climatology
}

\section{Hundred-kiloyear cycle queried}

\author{
Alan C. Mix
}

ONE of the major research issues of the past decade in palaeoclimatology has been to determine the cause of the $100-\mathrm{kyr}$ cycle, which has seemed to dominate the apparent fluctuations of the ice ages preserved in the geological record. In a recent paper $^{1}$, Bill Ruddiman and Maureen Raymo of Lamont-Doherty Geological Observatory add a new twist to this picture. Their detailed study of hydraulicpiston-cores taken by the Deep-Sea Drilling Project confirms earlier suggestions ${ }^{2}$ that the $100-\mathrm{kyr}$, ice-age cycle is a recent aberration, prevalent only during the past $800 \mathrm{kyr}$.

Milankovitch hypothesized ${ }^{3}$ in 1941 that the Earth's climate changes in response to the changing geometry of the Earth's orbit. He predicted climatic cycles with periods of about $23 \mathrm{kyr}$ (due to precession of the equinoxes, the circular wobble of the Earth's axis), 41 kyr (due to variations in the tilt of the Earth's axis) and $100 \mathrm{kyr}$ and $400 \mathrm{kyr}$ (due to the varying eccentricity of the orbit). Recently, palaeooceanographers studying microfossils from deep-sea sediments have developed timescales accurate enough to demonstrate convincingly the presence of these 'Milankovitch cycles' during the past several hundred thousand years.

The striking thing about this record is that the preserved 100 -kyr ice-age cycle is the strongest, even though the direct eccentricity-forcing is the weakest of the orbital effects. In addition to their small, direct influence on collection of sunlight by the Earth, eccentricity variations modulate the strength of the precession effect, which controls where on the Earth's orbit the seasons occur. For example, when the Earth's orbit is perfectly circular it does not matter where summer or winter occurs. When the orbit is eccentric, however, the Earth-Sun distance varies throughout the year. Hotter summers would occur in the Northern Hemisphere when June occurred at a point closer to the Sun, as it did 11,000 years ago.

The 100-kyr climate cycle has generally been explained ${ }^{5}$ by the relatively slow growth and fast melting of large ice sheets. Through this nonlinear mechanism, many believe that the ice sheets respond to the modulation of precession by eccentricity, and thus get their 100 -kyr cycle indirectly. This theory relies on the internal characteristics of ice sheets, their long (and nonlinear) time constants, to account for the observed 100 -kyr cycle.

This theory is now questioned. First, strong $100-\mathrm{kyr}$ climate cycles seem to have occurred before the late Cenozoic ice ages $^{6.7}$, implying that ice is not necessary to generate a $100-\mathrm{kyr}$ rhythm. And second, the new evidence of Ruddiman and Raymo ironically suggests that the $100-\mathrm{kyr}$ cycle is a rare occurrence for ice ages. This study confirms that the $100-\mathrm{kyr}$ rhythm of glaciation appeared within the past million years, and became dominant only within the past half-million years. A much longer interval of the late Cenozoic ice ages, from $\sim 2.4$ to $0.8 \mathrm{Myr}$, was almost completely dominated by the $41-\mathrm{kyr}$ tilt cycle.

The major question addressed by Ruddiman and Raymo is what caused the shift in rhythmic response of the ice ages to orbital forcing? They believe that evolution in character of the ice ages must result from some change in the external boundary conditions of climate (the configuration of land, sea, ice and atmosphere). They speculate that the rapid tectonic uplift of the Himalayas and parts of western North America during the past few million years has increased the sensitivity of the system, probably by inducing downstream meanders in the jet stream. These atmospheric waves would cause cold spots over eastern North America and Europe exactly where the large Northern Hemisphere ice sheets were located. Another theory, due to Pisias and Moore $^{2}$, suggests that the growth and decay times of smaller, land-based ice sheets of the early record were shorter than those of the more recent, larger, marine-based ice sheets. This might account for the growth of the $100-\mathrm{kyr}$ cycle through time, but leaves open the question of why the more recent ice sheets were bigger than the earlier ones. Ruddiman's and Raymo's suggestion may solve this problem.
As noted by Ruddiman and Raymo, many uncertainties remain that will keep geologists and climatologists busy for years. First, of course, is the problem of developing timescales for geological sections accurate enough to read the cyclic patterns of climate change. Because Ruddiman and Raymo tuned part of their time scale to the 41-kyr tilt cycle, it is not surprising that the 41-kyr cycle dominated their time series. It is unlikely, however, that their tuning could have erased a 100 kyr cycle from the record.

Second, exactly when the major uplift of the Himalayas occurred and how fast it was is unclear. Although some believe ${ }^{8}$ that much of the uplift took place within the past few million years, others ${ }^{9}$ believe the Himalayas reached essentially full height more than 20 million years ago; details of the last $3 \mathrm{Myr}$ are sketchy at best.

Third, how sensitive to topography are waves in the high-latitude wind fields? Different computer models give conflicting results for the cases of no-topography versus present-topography ${ }^{10,11}$. No models have been run for intermediate cases of continuous uplift. Of course, the addition of the ice sheets adds topography to the system, and these boundary conditions have yet to be explored fully in generalcirculation models of the atmosphere.

Finally, the observation of $100-\mathrm{kyr}$ climate cycles before the ice ages ${ }^{6,7}$, if correct, remains a mystery. If this rhythm is present during much of time before the onset of Northern Hemisphere glaciation, it may be that the interval of 41-kyr cycles from 2.4 Myr to $0.8 \mathrm{Myr}$ found by Ruddiman and Raymo is the anomaly, and that the resumption of $100-\mathrm{kyr}$ cycles at $0.8 \mathrm{Myr}$ is simply the return to normal behaviour. At this point, there are more questions than answers. With the addition of long time series on climate change coming from the Ocean Drilling Program the rapid development of climate models, and the refinement of tectonic reconstructions, the next few years should see interesting developments (and more surprises) in this field.

1. Ruddiman, W.F. \& Raymo, M. Phil. Trans. R. Soc. (in the press).

2. Pisias, N.G. \& Moore. T.C. Jr Earth planet. Sci. Lett. 52, $450-458$ (1981)

3. Milankovitch. M. Canon of Insolation and the Ice Age Problem (Royal Serbian Academy, Belgrade, 1941).

4. Imbrie, J. et al. in Milankovitch and Climate (eds Berger et al.) 269-305 (Reidel, Dordrecht, 1984).

5. Imbrie, J. \& Imbrie, J.Z. Science 194. 943-952 (1980)

6. Herbert, T.D. \& Fischer, A.G. Nature 321, 739-743 (1986).

Olsen, P.E. Science 234, 842-848 (1986)

8. Dongsheng, L. \& Menglin, D. in The Evolution of the East Asian Environment (eds Whyte et al.) 11-40 (Hong Kong University, 1984)

9. Seeber, L. \& Armbruster, J.G. Tectonophysics 105, 263 278 (1983).

10. Manabe, S. \& Terpestra, T.B. J. atmos. Sci. 31, 3-42 (1974).

11. Kasahara, A. \& Washington, W.M. J. atmos. Sci. 28, 657 701 (1971).

Alan C. Mix is at the College of Oceanography, Oregon State University, Corvallis, Oregon 97331, USA. 